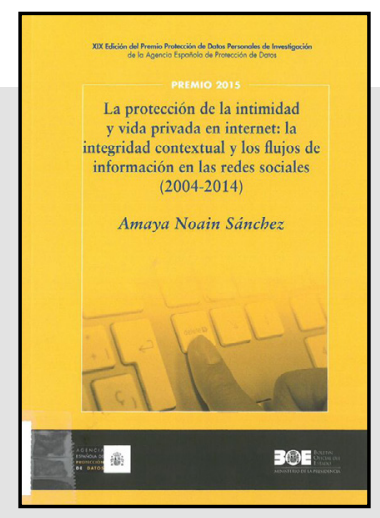

La protección de la intimidad y vida privada en internet: la integridad contextual y los flujos de información en las redes sociales (2004-2014) Amaya Noain Sánchez Agencia Española de Protección de Datos, Madrid, 2016

\title{
La protección de la intimidad y vida privada en internet: la integridad contextual y los flujos de información en las redes sociales (2004-2014)
}

as redes sociales se han convertido en una herramienta de comunicación
y contacto habitual para millones de personas". Tras esta frase tan certera
como lapidaria escrita en el prólogo de este libro por Mar España Martí, directora de la Agencia Española de Protección de Datos, se encuentran una serie de preguntas que casi todos los usuarios nos hemos hecho en más de una ocasión. Así, por ejemplo, ¿qué pasa con los datos que introducimos cada vez que tecleamos nuestro nombre en alguna red social? Este es el mismo interrogante que se planteó Amaya Noain Sánchez y que motivó el libro que estamos reseñando, merecedor del Premio Protección de Datos Personales de Investigación 2015 en la modalidad de investigación.

Así pues, y gracias a la tesis doctoral precursora de este premio, podemos conocer los riesgos latentes en el uso de las redes sociales a través de la Web 2.0, y los problemas a los que nos enfrentamos los usuarios al intentar preservar nuestra intimidad en dichos medios. Estos problemas han cambiado sustancialmente la forma de entender la vida privada y pública, originando una estrecha línea invisible entre lo qué queremos mostrar y lo qué mostramos. Esa línea no siempre se sitúa donde nos gustaría, acarreando, en ocasiones, problemas y más de un disgusto. 


\section{RESENAS Y REVISIONES}

De esta forma, y tras un minucioso análisis de la literatura existente, así como de la popular red social Facebook, la autora constata el necesario conocimiento de la propia protección de las informaciones relativas a la vida privada de los usuarios. Este conocimiento nos permitirá tomar decisiones críticas y conscientes encaminadas a la protección de nuestra intimidad e intereses dentro del mundo virtual.

Si bien hasta este punto la información que nos presenta la autora es digna de elogio, consideramos que la mayor aportación reside en las recomendaciones posteriores que nos hace. Estas pasan por una necesaria implementación de medidas educativas en todos los niveles y edades. Medidas que permitan desarrollar unas competencias específicas encaminadas al dominio de las Tecnologías de la Información y la Comunicación en general, y de Internet y las redes sociales en particular. Por otro lado, se proponen una serie de cambios técnicos referidos a la inclusión de la protección "por defecto" o la reformulación del "consentimiento informado", dando lugar al "consentimiento informado por capas". De esta forma, si el conocimiento sobre los derechos relativos a la protección de datos por parte de todos los actores implicados se convirtiese en un imperativo legal y moral, y los mecanismos a través de los cuales se llega a ese acuerdo son los adecuados, se podrían atajar la mayoría de los problemas que surgen a posteriori.

Se trata, en definitiva, de un minucioso documento de 550 páginas distribuidas en cinco partes que organizan una investigación, desde sus orígenes hasta la exposición de unas conclusiones bien argumentadas, magníficamente expuestas $\mathrm{y}$, sobre todo, de utilidad en nuestra sociedad actual. Así pues, nos cuesta responder la pregunta de a quién le puede interesar este libro, ya que consideramos que el interrogante debería ser a quién no.

\section{Diego Calderón-Garrido}

Doctor en Historia del Arte por la Universidad de Barcelona Profesor de la Universidad Internacional de La Rioja 